that the material brought back by the expedition will also help to clear up the vexed question as to the races of the Puffin (Fratercula arctica), as to which there is much division of opinion.

Some interesting observations bearing on the sexual selection theory were made by Julian $\mathrm{S}$. Huxley on the Red-throated Diver (Colymbus stellatus), confirming and extending the conclusions reached by him in his paper on the courtship of Podiceps cristatus (Proc. Zool. Soc., I9I4). After the birds have mated for the season, elaborate courtship ceremonies take place between the mated pair. At times the two birds swim near each other with necks arched and the open beak half submerged, uttering a special cry. At others, one bird will dive all round and about the other, sometimes emerging almost vertically from the water, as does Podiceps. The active performer in such cases may be either the male or the female.

There thus exist, as in the Crested Grebe, mutual nuptial ceremonies. The bird's bright colouring and special nuptial activities are connected with the bird's sexual life, but not secondary sexual characters-epigamic, but not sex-limited.

Of particular interest were the observations made on the period during which the birds are separating into pairs for the season. At this time, too, they indulge in special ceremonies, in which, however, rarely two, but usually three (or even four), individuals participate. The birds submerge the whole body with the exception of the breast; the neck is thrust slightly forward and the head held out, so that the appearance is that of a miniature Plesiosaur. In this attitude the birds plough through the water, as if running races. This ceremony was never observed later, and is certainly connected with the choice of mates. Most remarkable of all, it appears almost certain that tw̧o females may thus " compete" for a single male as well as vice versa. In any event, we have as a new feature that in this species the mutual or common nuptial activities of the two sexes extend even into the pairing-up period, where, if anywhere, sex-limited display and Darwinian sexual selection might be expected. This period was not observed in the previous work on Podiceps. The need for some theory of " mutual selection" to supplement the Darwinian theory of sexual selection is thus further emphasised.
Favourable opportunities for observing the nuptial activities of Phalaropes and Purple Sandpipers, in both of which reversed sexual coloration and habits occur, were unfortunately very few. It is, however, suggested that (I) the pressure of Arctic life acts as an encouragement to small size in the waders; (2) that, per contra, the short breeding season requires the eggs to be large, in order that their development may be hastened; this, in its turn, will limit the reduction in size of the female; (3) the female will therefore tend to be bigger than the male; (4) in almost all birds (excluding Raptcres) brighter colour of the male accompanies larger size. Presumably size, pigmentation, and psychological activity are all controlled together by the endocrine secretion of the gonad. It is thus probable that larger size of the female in these species will be associated with that type of metabolism which favours more intense pigmentation; (5) the more protectively coloured male could then more advantageously undertake incubation.

A discussion of this suggestion, however, would involve the handling of large bodies of evidence. It is, in any event, clear that the condition has developed from one in which both sexes were similarly coloured, and both shared the duties of incubation.

To sum up, we have here a series of nearly three hundred skins as well as about five hundred eggs, together with full diaries and field notes from members of the expedition. It is hoped that the reports on these collections will embody what is already known of the Spitsbergen and Bear Island group, and provide us with a dependable and handy manual on the birds of the archipelago. The com ing of the oil engine has already affected the fauna considerably, and probably will do so even more in the future, and it is important to record the changes of the last ten or fifteen years. Koenig's fine work is bulky and expensive, and a concise account of the bird life, embodying the results of the present expedition, would be a most valuable work of reference as well as a permanent memorial of what is perhaps the only serious ornithological work undertaken by English men or women in the Arctic since Mr. Henry Pearson's last voyage to Russian Lapland more than twenty years ago, with the sole exception of Miss Haviland's adventurous journey to the mouth of the Yenisei in r9r4.

\title{
The Present Position of the Theory of Descent, in Relation to the Early History of Plants. ${ }^{1}$
}

\section{By Dr. D. H. ScotT, F.R.S.}

I T has long been evident that all those ideas of evolution in which the older generation of naturalists grew up have been disturbed, or, indeed, transformed, since the re-discovery of Mendel's work and the consequent development

1 Abridged from the presidential address delivered to Section K (Botany) of the British Association at Edinburgh on September 9. NO. 2709 , vOL. I08] of the new science of genetics. Not only is the "omnipotence of natural selection" gravely impugned, but also variation itself, the foundation on which the Darwinian theory seemed to rest so securely, is now in question.

The small variations, on which the natural selectionist relied so much, have proved, for the 
most part, to be merely fluctuations, oscillating about a mean, and therefore incapable of giving rise to permanent new types. The well-established varieties of the Darwinian, such as the countless forms of Erophila verna, are now interpreted as elementary species, no less stable than Linnean species, and of equally unknown origin. The mutations of De Vries, though still accepted at their face value by some biologists, are suspected by others of being nothing more than Mendelian segregates, the product of previous crossings; opinion on this subject is in a state of flux. In fact, it is clear that we know astonishingly little about variation. Dr. Lotsy, indeed, proposes to dispense with variation altogether, and to find the true origin of species in Mendelian segregation; inheritable variability, he believes, does not exist; new species, on his bold hypothesis, arise by crossing, and so, as he points out, we may have an evolution, though species remain constant. Thus everything apparently new depends on a re-combination of factors already present in the parents. "The cause of evolution lies in the interaction of two gametes of different constitution."

I am aware that very surprising results have been obtained by crossing. Nothing could well have been more striking than the series of Antirrhinum segregates which Dr. Lotsy showed us some years ago at a meeting of the Linnean Society; and now we hear of an apetalous Lychnis produced by the crossing of normally petaloid races. We do not know yet to what extent that sort of thing goes on in Nature, or what chance such segregates have of surviving. Still, if one may judge by Dr. Lotsy's experimental results, ample material for natural selection to work on might be provided in this way.

Dr. Lotsy's theory that new species originate by Mendelian segregation, if true, would have the advantage that it would make quite plain the meaning of sexual reproduction. Hitherto there has been a good deal of doubt; some authorities have held that sexual reproduction stimulated, others that it checked, variation. But, if we eliminate variation, and rely solely on the products of erossing, we get a clear view-_" species, as well as individuals, have two parents "; sexual reproduction can alone provide adequate material for new forms, and can provide it in unbounded variety.

Again, though Dr. Lotsy himself is far from sanguine on this point, the crossing theory might be helpful to the evolutionary morphologist, for breeding is open to unlimited experiment, and we might hope to learn what kinds of change in organisms are to be expected. For example, the Lychnis experiment shows how easily a petaloid race may become apetalous. Such results might ultimately be a great help in unravelling the course of evolution in the past. We should gain an idea of the transformations which might actually have taken place, excluding those which were out of the question. At present all speculation on the nature of past changes is in the air, for variation itself is only an hypothesis, and we have to decide, quite arbitrarily, what kind of variations we think may probably have occurred in the course of descent. One need only recall the various theories of the origin of the seed from the megasporangium to realise how arbitrary such speculations are.

But, while recognising certain advantages in the theory of the origin of species by crossing, it is not for me to pronounce any opinion as to its truth. It is only the present position of the question that concerns us to-day. Some modern geneticists believe that there is evidence for mutation by the loss of factors, apart from the effects of crossing. Dr. Lotsy considers that such changes, if proved, can afford no explanation of progressive evolution. "Evolution by a process of repeated losses is inconceivable." It has, however, been pointed out by Dr. Agnes Arber, in her recent admirable book on water-plants, that, on any theory of evolution, "what organisms have gained in specialisation they have lost in plasticity." This is true, but it is not clear that this admitted loss of potentialities is the same thing as the loss of factors, in the sense of genetics.

Turning for a moment to Darwin's own theory of the origin of species by means of natural selection, the efficacy of the latter in weeding out the unfit is, of course, still acknowledged, and some geneticists allow it a considerable rôle. But there is a strong tendeney in these days to admit natural selection only as a " merely negative force," and as such it has even been dismissed as a "truism." Now Darwin's great book was most certainly not written to enunciate a truism. $\mathrm{He}$ regarded natural selection as " the most important, but not the exclusive, means of modification ", " Origin of Species," p. 4). It was the continual selection of the more fit, the "preservation of favoured races," on which he relied, and not the mere obvious elimination of the unfit, and this great idea (so imperfectly understood by many of his contemporaries and successors) he worked out with astonishing power, in the light of the changes which man has produced, with the help of his own artificial selection.

It may be that the theory of natural selection, as Darwin and Wallace understood it, may some day come into its own again; certainly it illuminated, as no other theory has yet done, the great subject of adaptation, which to some of us is, and remains, the chief interest of biology. But in our present total ignorance of variation and doubt as to other means of change, we can form no clear idea of the material on which selection has had to work, and we must let the question rest.

For the moment, at all events, the Darwinian period is past; we can no longer enjoy the comfortable assurance, which once satisfied so many of us, that the main problem had been solved-all is again in the melting-pot. By now, in fact, a new generation has grown up that knows not Darwin.

Yet evolution remains-we cannot get away NO. 2709 , VOL. IO8] 
from it, even if we hold it only as an act of faith, for there is no alternative, and, after all, the evidence of palæontology is unshaken. I have thought it fair to lay stress on the present state of uncertainty in all that concerns the origin of species. On another occasion I even ventured to speak of the return of " pre-Darwinian chaos." But out of this chaos doubtless light will come. Last year, during a joint discussion on genetics and palæontology, I specially remember a remark by Miss Saunders, our then president, that Mendelism is a theory of heredity, not of evolution-a caution not unneeded, though, as the crossing hypothesis shows, the connection between the two conceptions may prove to be a very close one.

Genetics is rendering the greatest service to biology generally in ensuring that organisms shall be thought of as races, not as isolated individuals, mere chemical and physical complexes, at the mercy of the environment. The whole tendency of modern work is to show that in living things heredity is supreme. An organism is what it is by virtue of the constitution of the germ-plasm derived from its parents. Dr. Church says that " the more fundamental reactions, as expressed in morphological units of construction, have been established as constants beyond any hope of change." This statement is an important one for the palæontologist, for all our attempts to trace descent rest on the assumption that, in a general sense and as regards certain well-established characters, "like breeds like."

The question, What do we mean by a "species"? is far too difficult a matter to discuss now. Whatever we may think of Darwin's theory, his "Origin of Species" is at any rate a classic, and I believe we cannot do better than continue to use the word in the same sense as Darwin used it-i.e. essentially in the sense of a Linnean species.

That many Linnean species are real units of a definite order is generally admitted. Dr. Lotsy himself dwells on their distinctness, which depends on their usually not inter-crossing, and appears to be shown by the fact that among animals members of the same species recognise each other as such and habitually breed together. Such habitual breeding together under natural conditions is perhaps the best test of a species in the Linnean sense. "The units within each Linneon (=species) form an inter-crossing community." (Lotsy.) He adds: "Consequently it is Nature itself which groups the individuals to Linneons." These "pairing communities " have recently been re-christened by Dr. Lotsy "syngameons," a good name to express this aspect of the old "species."

I do not propose in these brief remarks to venture on that well-worn subject the inheritance of acquired characters-i.e. of such characters as are gained during the lifetime of the individual by reaction to the environment. There has always been a strong cross-current of opinion in favour of this belief, especially, in our own time, in the form of "unconscious memory," so ably advocated by Samuel Butler and supported by Sir Francis Darwin in his presidential address to the British Association at Dublin. Professor Henslow, as we all know, is a veteran champion of the origin of plant structures by self-adaptation to the environment. On the other hand, some geneticists roundly deny that any inheritance of somatically acquired characters can take place. In any case, the evidence, as it seems, is still too doubtful and inadequate to warrant any conclusion, so, however fascinating such speculations may be, I pass on.

To bring these introductory remarks to a close, we see that while the theory of descent or evolution is undisputed, we really know nothing certain as to the way in which new forms have arisen from old. During the reign of Darwinism we commonly assumed that this had happened by the continual selection of small variations, and we are no longer in a position to make any such assumption.

We have been told on high authority that " as long as we do not know how Primula obconica. produced its abundant new forms it is no time to discuss the origin of the Mollusca or of Dicotyledons." (Bateson.) Yet this is just the kind of speculation in which a palæontologist is apt to indulge, and if kept off it he would feel that his occupation was gone! However, so long as we may believe, as already said, that, on the whole, like breeds like, that grapes do not spring from thorns or figs from thistles, there is perhaps still sufficient basis for some attempt to interpret the past history of plants in terms of descent. But certainly we have learnt greater caution, and we must be careful not to go far beyond our facts. and, in particular, to avoid elaborate derivations of one type of structure from another where the supposed transitional forms have but a purely subjective existence; we have realised the diffculty of tracing homologies. We may still be allowed to seek affinities, even where we cannot trace descent. And though we may sometimes go a little beyond our tether and give rein to bolder speculations, there is no harm done so long as we know what we are doing, and there may be even some good in such flights if our scientific use of the imagination serves to give life to the dry bones of bare description. On this subject I am somewhat more optimistic than Dr. Lotsy, who, abandoning his "Stammesgeschichte" point of view, has dismissed all attempts at phylogenetic reconstruction as "fantastic.",

There are some questions of the highest interest that at present can scarcely be approached in any other but a speculative way. Within the last year or two new points of view have thus been opened out. For example, Dr. Church's able essay on "Thalassiophyta and the sub-aerial transmigration" has brought vividly before us the great change from marine to terrestrial life. Dr. Church puts the actual conquest of the land in the foreground. We watch the land slowly rising toward the surface of the primeval ocean, 
the rooted sea-weeds succeeding the freeswimming plankton, and then the continents slowly emerging and the drama of the transmigration, as the plants of the rock-pools and shallows fit themselves step by step for sub-aerial life when the dry land appears. It is a striking picture that is thus displayed to our viewwhether in all respects a faithful one is another question; we must not expect impossibilities. The doubts which have been raised relate first to the assumed world-wide ocean, which seems not to be generally accepted by geologists. If continental ridges existed from the first (i.e. from the original condensation of watery vapour to form seas), the colonisation of the land may have followed other lines and have happened repeatedly. Perhaps, after all, that would not greatly affect the botanical aspects of the transmigration.

Dr. Church believes that the chief morphological characters of the land flora were first outlined in the sea; that such characters were not newly assumed after transmigration, but that they merely represent an adaptation to sub-aerial conditions of a differentiation already attained at the phase of marine phytobenthon (rooted sea-weeds). At the same time it is not suggested that any existing class of sea-weeds can be taken as representing the ancestry of the land flora; the transmigrant races are, as Algæ, extinct-they may have been Green Algæ of a high grade of organisation, on a level now perhaps most nearly represented by the highest of the Brown Sea-weeds.

Thus the transmigrants, which were destined to beoome the parents of the land flora, are pictured as already highly organised and well differentiated plants, which only needed to provide themselves with absorptive instead of merely anchoring roots, and with a water-conducting system (xylem and stomata) in order to fit themselves for sub-aerial life, while, on the reproductive side, the great change remaining to be accomplished was the adaptation of the spores to transport by air instead of by water.

Some botanists find a difficulty in accepting the suggestion that plants already elaborately fitted out for a marine life could have survived the transition, however gradual, to a totally different environment. Such thinkers prefer to believe that lower forms may have been more adaptable, and that morphological differentiation had, in a great degree, to start afresh when the land was first invaded. My own sympathies, I may say, are here with Dr. Church; for I have long inclined to the belief that the vascular plants were, in all probability, derived from the higher Thallophytes. The view of the late Prof. Lignier, now so widely accepted, that the leaf, at least in the megaphyllous or fern-like vascular plants, was derived from specialised branch-systems of a thallus, assumes, at any rate, that the immediate ancestors possessed a well-developed thallus, such as is now known only among the higher Algæ.

The question now arises, how far have we any evidence from the rocks which may bear on the transmigration and on the nature of the early land flora? Quite recent discoveries, especially those from the famous Rhynie Chert-bed, have shown that in Early. Devonian times certain remarkably simple land-plants existed, which in general configuration were no more advanced than some very ordinary sea-weeds of the present day. At the same time these plants were obviously fitted for terrestrial life, as shown by the presence of a water-conducting tissue and stomata, and by the manifestly air-borne spores. These simplest land-plants are the Rhyniaceæ (Rhynia and Hornea), while the third genus, Asteroxylon, was more advanced and further removed from any possible transmigrant type.

Dr. Arber was so impressed by the primitive character of Rhynia (the only one of these genera then known) that he boldly called it a Thallophyte, while recognising, in respect of anatomical structure, an intermediate position on the way to Pteridophyta. This is not really very different from the view taken by the investigators themselves, though they call the plants Pteridophytes, which they certainly are if we go by internal structure rather than external morphology. But if, as Kidston and Lang suggest, the Rhyniaceæ "find their place near the beginning of a current of change from an Alga-like type of plant to the type of the simpler vascular Cryptogams," they must have been very primitive indeed, and might even be regarded as fairly representing the true transmigrants which had not long taken to the land.

It is true that the Middle Devonian is much too late a period for the original transmigration (I believe there is some evidence for land-animals in the Lower Silurian), but one may argue that some of the transmigrant forms may have survived as late as the Devonian, just as the Selaginella type seems to have gone on with little change from the carboniferous to the present time. There must have been many such survivals of earlier forms in the Devonian period, if Arber was right in regarding all the characteristic plants of the Psilophyton flora as " much more probably Thallophyta than Pteridophyta." There is, in fact, no doubt that the earlier Devonian flora is turning out to have been on the whole more peculiar and more unlike the higher plants than we realised a few years ago. The Early Devonian plants cannot usually be referred to any of the recognised groups of Pteridophytes, and this is not owing to our imperfect knowledge, for it is just in those cases where the plants are most thoroughly known that their unique systematic position is most manifest. Arber called all the plants in question "Procormophyta " - an appropriate name. As Kidston and Lang point out in their later work, the three groups-Pteridophyta, Bryophyta, and Algæ-are brought nearer together by the Rhynie fossils.

Yet there is evidence that about the same period stems with the highly organised structure of Gymnospermous trees already existed. I refer to NO. 2709 , vOL. IO8] 
remains of which Palaeopitys Milleri, from the Middle Old Red Sandstone of Cromarty, is the type. We need much further investigation of these higher forms of Early Devonian vegetation, but we know enough to impose caution on our speculations.

The Rhyniaceæ, at all events, were leafless and rootless plants. In one species of Rhynia and in Hornea the aerial stems are entirely without any appendages, while in the other Rhynia there are hemispherical swellings, which have been identified by Arber with certain states of the spines in Psilophyton. The emergences of $R$. GwynneVaughani have been interpreted as nascent leaves, but more recent observations, showing their late histological origin, have rendered this hypothesis very doubtful.

In Asteroxylon, a higher plant altogether, the stem is clothed with quite distinct leaves, though they are somewhat rudimentary as regards their vascular supply. Have we, in these plants, and others of contemporary date, the first origin of the leaf from a mere non-vascular emergence, or had reduction already begun, so that in Rhyniaceæ, for example, the leaves were in the act of disappearance? In the former case we should be assisting at the birth of Lignier's phylloids, the microphylls of the Lycopod series.

But the opposite view may also be tenable. We have already seen that these plants have been referred both to the Pteridophytes and the Thallophytes; they also show signs of Bryophytic affinities, and I understand that it has even been proposed to include them in the Bryophyta, in which case every possible view will be represented. The Sphagnum-like structure of the columellate sporangium or sporogonium of Hornea and Sporogonites may justify the Bryophytic attribution, and it is then, of course, easy to extend it to Rhynia. If we were to adopt this opinion we should probably have to regard these simple Devonian plants as representing stages in the reduction of the sporophyte to a sporogonium, the leaves being already nearly or quite lost, while the branched thallus was still much in excess of the simple seta of the modern Moss or Hepatic. Naturally we know nothing of the gametophyte, so that the material for comparison is limited. Kidston and Lang, however, have recently pointed out that the presence of sporetetrads clearly indicates the existence of a gametophyte.

I make no attempt to decide between these views. There can be no reasonable doubt that the Psilophytales generally represent an earlier phase of cormophytic life than any of the groups previously recognised. But we must not assume that all their characters were primitive. It has been pointed out that the Rhyniaceæ were peat plants, and that the peat flora is apt to be peculiar. Under such conditions it is not improbable that a certain amount of reduction may have already been undergone, though this is not the view taken by the investigators.
The recent work on the Early Devonian flora has wide bearings. It has long been noticed that among the fossils of that period no typical fernfronds are found. Those remains which are most suggestive of fern-like habit consist merely of a naked, branched rachis. It used to be assumed that the absence of a lamina might be explained by bad preservation. But, as Prof. Halle points out, the chief reason for condemning the preservation as bad was the fact that a lamina was absent!

The evidence really seems to indicate that the so-called fronds of that age did not possess a leaf-blade. As Prof. Halle says: "In the Lower Devonian, finally, we find frond-like structures bearing sporangia, but no fronds with developed laminæ. One can hardly escape the conclusion that the 'modified' fertile fronds may represent the primitive state in this case and that the flattened pinnules are a later development, as suggested by Prof. Lignier." These naked fronds may, in fact, be regarded as the little-differentiated branches of a thallus.

The evidence, as at present understood, seems to suggest that, in the earlier Devonian flora, ferns, properly so called, may not yet have been in existence. The predecessors of the ferns were there, no doubt, but not, so far as we know, the ferns themselves. Yet it seems that highly organised stems of a gymnospermous type were already present at about the same period. Thus the evidence from the older Devonian flora, so far as it goes, materially supports the opinion that the seed plants cannot have arisen from ferns, for the line of the Spermophyta seems to have been already distinct at a time when true ferns had not yet appeared.

The idea, which I once advocated, that the Gymnosperms were derived, through the Pteridosperms, from the ferns must, I think, be given up, on grounds which were stated two years ago at the Bournemouth meeting of the Association. It is safer to regard the Pteridosperms, and therefore the seed plants generally, as a distinct stock, probably as ancient as any of the recognised phyla of vascular Cryptogams, and derived from some unknown and older source. At the same time the striking parallelism between the Pteridosperms and the true ferns must be recognised. These views are essentially in agreement with those previously expressed by my friend Dr. Kidston.

The significance of the Pteridosperms has perhaps been somewhat misunderstood. It now seems that they do not, as some of us once imagined, indicate the descent of the seed plants from ferns, but rather show that the seed plants passed through a fern-like phase; they ran a parallel course with the true cryptogamic ferns, and, like them, sprang from some quite early race of land plants, such as Rhynie has revealed to us. But the phylum was never any more fernlike than the Pteridosperms themselves.

On our hypothesis, the Upper Palæozoic phyla, with which we have to reckon, are the Pterido- 
sperms (representing the early phase of the seed plants), the ferns, the Sphenophylls, the Equisetales, and the Lycopods. These five lines were probably all well differentiated in the Upper Devonian flora.

When we get back to the Middle and Lower Devonian the case is completely altered. 'Not one of the five phyla is here clearly represented, unless it be the Spermophyta; for these we have the evidence of apparently gymnosperm-like stems. Thus the field is left absolutely open to speculation. We may imagine either that the various phyla converged in some early vascular stock (illustrated by the Psilophytales), or that they ran back in parallel lines to independent origins among the transmigrant Algæ and, perhaps further still, to separate races of purely marine plants. Both views are represented in the publications of recent authors.

Dr. Arber, in his "Devonian Floras," maintained the early existence of three distinct lines of descent: the Sphenopsida, Pteropsida, and Lycopsida. Each of the three lines is described as descended from thallophytic Algæ of a distinct type. Thus Arber's view was decidedly polyphyletic.

Dr. Church, from quite a different point of view, arrives at somewhat similar conclusions, but he goes further. He says: "Speaking generally, it appears safer to regard a 'race' or 'phylum' as the expression of a group of organisms which derived their special attributes from the equipment of a preceding epoch, if not in one still further back. Thus all the main lines of what is now land flora must have been differentiated in the Benthic epoch of the sea (i.e. as algal lines), as all algal lines were differentiated in the Plankton phase. The possibility is not invalidated that existing groups of land flora may trace back their special line of progression to the flagellated life of the sea, wholly independently of one another (Pteridophyta)."

Thus the idea of independent parallel lines of descent is carried to its extreme limit. "Each phylum goes back the whole way, without any connection with anything else." Of course, this thorough-going polyphyletic conception is involved in the doctrine already mentioned that morphological differentiation was attained in the sea before the transmigration.

I have cited Dr. Arber and Dr. Church as independent representatives, approaching the question from quite different sides, of the polyphyletic or parallel-phyla hypothesis. The opposite view, of convergent monophyletic races, is also well supported. Prof. Halle, after speaking of the possible relation of the Psilophyton type to Lycopods on one hand and ferns on the other, adds: "From this point of view the whole pteridophytic stock would be monophyletic, the Lycopsida and the Pteropsida being derived from a common form already vascular. It would not thus be necessary to assume a parallel evolution of a similar vascular system along two different lines."

NO. 2709, VOL. IO8]
Kidston and Lang, in the light of their Rhynie discoveries, regard Halle's survey as" "a fair statement of the present bearing of the imperfectly known facts." They add: "The geological age and succession of the Early Devonian plants are, on the whole, consistent with the origin of the various groups of vascular Cryptogams from a common source." We have already referred to the bryophytic features, which have been recognised in the Rhyniaceæ. Kidston and Lang make use of these to extend their tentative conclusions to the Bryophyta. In concluding their third memoir they say: "In Rhynia and Hornea we have revealed to us a much simpler type of vascular Cryptogam than any with which we were previously acquainted. This type suggests the convergence of Pteridophyta and Bryophyta backwards to an algal stock. The knowledge of Asteroxylon confirms and enriches our conception of a more complex but archaic type of the vascular Cryptogams, which supports the idea of the divergence of the great classes of Pteridophyta from a common type, and links this on to the simpler Rhyniaceæ." The monophyletic view, though stated with appropriate caution, could not be more clearly expressed

It is evidently impossible to decide between the two theories in the present state of our knowledge; we are now only beginning to acquir some conception of the vegetation of Early Devonian times, The discovery, however, of the existence at that period of an unexpectedly simple race of vascular plants to some extent favours a monophyletic interpretation. To some minds, too, the important points in which all existing Pteridophyta, however diverse, agree will still suggest a common origin not too remote. Among such common characters may be mentioned the alternation of generations with the sporophyte predominant; the development both of the spores and the sexual organs; and the histology, especially of the vascular system and the stomata. The community of reproductive phenomena is explained by $\mathrm{Dr}$. Church on the principle that reproductive phases are inevitable and are therefore the same in all phyla. A like explanation may to a certain extent be applicable to somatic features, some of which may be the necessary consequences of the sub-aerial transmigration. Thus a polyphyletic hypothesis may no doubt be justified, but it urgently needs to be supported by further evidence of the actual existence of separate stocks among the earliest available records of a land flora.

The study of fossil botany has led to results of the utmost importance in widening our view of the vegetable kingdom and helping to complete the natural. system, to use Solms-Laubach's old phrase once more. One need mention only the Mesozoic Cycadophytes, the Cordaitales, the Pteridosperms, the Palæozoic Lycopods and Equisetales, the Sphenophylls, and now, most striking of all, the Psilophytales, to recall how much has been gained. We have indeed a wealth of accumulated facts, but from the point of view 
of the theory of descent they raise more questions than they solve. In this address I have briefly touched on some of the most general and most speculative problems in the hope of giving an opening for discussion. It might have been more profitable to deal in detail with definite facts of observation, but recent: discoveries have brought us face to face with the great questions of descent among plants. However imperfect our data may be, both as regards the method and the course of evolution, the problems suggested, nevertheless, make urgent claims on our attention.

\section{The Shackleton-Rowett Oceanographic and Antarctic Expedition.}

\section{By Dr. Hugh Robert Mill.}

THE Shackleton-Rowett expedition, the preliminary plans of which were outlined in Nature for July 7, p. 602, left St. Katherine's Dock in the Quest on Saturday, September I7, remained at Sheerness for a few days to complete the fitting of the wireless telegraphy apparatus, and sailed from Plymouth on Saturday last, September 24, at 5 p.m.

So much publicity has been given to the plans and prospects of this expedition, and such stress laid by headlines and large type on the minor incidents of preparation and departure, that one reader might be excused if he viewed it all as what, for lack of a more ancient and decorous term, he might be tempted to call a mere stunt; while another of a more generous disposition could scarcely be blamed for looking on it as a great oceanographical expedition. As a matter of fact, it is designed to be neither the one nor the other. The Quest is a very small vessel, and she has started on a very big voyage, full of dangers and risks that it is probable no committee of geographical or nautical experts would recommend any selected leader to undertake; but no such committee was created or consulted, and Sir Ernest Shackleton bears on his own broad shoulders all the responsibility for the plan of the expedition, the choice of his comrades, and the fight with the very real difficulties of a great and romantic adventure. Even if no scientific results were aimed at, this reyival of the old spirit of maritime knight-errantry which has invigorated our sea-history since Elizabethan days is a thing to be proud of and grateful for in an age of disillusion, low ideals, and love of ease. The members of the expedition include the most experienced polar explorers and men who have been trained in the almost incredible hardships of minesweepers, submarines, and " $Q$ "-ships.

Sir Ernest Shackleton has, however, a very clear and useful programme of scientific work, in which he sought the advice and secured the help of many authorities, including the Admiralty and the Air Ministry. He has not tried to make the Quest's voyage a second Challenger expedition, or in any way to anticipate the renewal of the large-scale oceanographical research ably sketched out by Prof. Herdman and wisely postponed to a more convenient, and, we trust, not very far distant, season. The Quest is fitted with the latest machines for deep-sea soundings, and if her voyage is completed along the route projected the results should be of great importance, espe- cially in the Enderby quadrant of the Antarctic. Some may be inclined to doubt the possibility of taking exact soundings from so small a vessel in high seas, but in the early days of telegraph-cable surveying with the crudest appliances excellent results were obtained, in depths far more than a thousand fathoms, from sailing vessels smaller than the Quest. No surveying ship probably has been better equipped for fixing accurate positions, as it should be possible to rate the chronometers by wireless time-signals during the greater part of the cruise. Deep-sea temperature observations and the collection of water-samples to be preserved for examination on shore should also be possible. The size of the ship makes it hopeless to attempt deep-sea dredging or trawling, but shallow-water dredging will no doubt be carried out when occasion offers, and the collection of plankton will be greatly facilitated by the low freeboard and comparatively slow speed of the ship.

Much interest attaches to the meteorological work to be done on board, and especially to the upper-air investigations for which provision has been made by the Meteorological Office. The small seaplane carried by the Quest will be very useful in piloting the vessel in ice and in the search for doubtful islands if it can be put together successfully and transferred safely from the ship to the sea and back again; but this part of the equipment must be viewed as an experiment the success of which is not to be acclaimed until it has been proved. Magnetic observations will, it is hoped, be made a special feature of the scientific work, and for the first time, we believe, a gyroscopic compass will be carried into high latitudes, where its indications should be of extreme value, as the track should carry the Quest across the region of maximum change of variation where the magnetic needle is of least value. Opportunities will doubtless occur for magnetic work on ice-floes and perhaps also on islands if local attraction is not too strong.

The personnel of the Expedition was announced as follows :-

Sir Ernest Shackleton, leader and captain; Commander Frank Wild, second-in-command; Commander Frank Worsley, hydrographer and sailing-master; Lieut.-Commander D. G. Jeff rey, navigator; Major A. H. Macklin, surgeon; Capt. L. D. A. Hussey, meteorologist; Lieut. A. J. Kerr; chief engineer; Major R. 'Carr, airman; Capt. G. V. Douglas, geologist; Capt. G. 